\title{
A STOCHASTIC GROUND MOTION MODEL FOR THE URBAN ENVIRONMENT
}

\author{
P. CACCIOLA AND A.TOMBARI
}

School of Environment and Technology, University of Brighton, Cockcroft Building Lewes Road BN2 4GJ, Brighton, UK.

\begin{abstract}
Nowadays stochastic ground motion models used for the seismic analysis and design of structures take into account the soil deposit only, disregarding the presence of existing buildings nearby. However, it is well known that ground motion in urban environment is modified by the presence of buildings, mainly due to the radiation energy emitted from a vibrating structure in the soil that alters the seismic free field motion. This study is a first attempt to propose a stochastic ground motion analytical model able to take into account the influence of the urban environment. A simplified discrete model is developed so to consider the influence of the radiated wave field into the free field ground motion. Comparison in terms power spectral density functions and peak ground acceleration determined from the proposed ground motion model and those determined through conventional approaches are carried out. Numerical results clearly show the efficiency of the proposed model to capture this complex phenomenon in the stochastic seismic analysis of structures by improving the accuracy of the estimation of the peak response of above $30 \%$. Limits of the proposed formulation are also discussed.
\end{abstract}

Keywords: Stochastic ground motion model, seismic response, urban environment, seismic site-city interaction.

\section{Introduction}

The definition of a reliable earthquake induced ground motion model is a still open public safety issue that need to be addressed to better predict the probability of failure of structures and infrastructures and to protect ultimately human lives. There is nowadays no universal recognized earthquake ground motion model although progresses have been made in the last few decades toward the refinement of stochastic models encompassing physical and/or seismological parameters (see e.g. Deodatis, [1]; Pousse et al. [2], Spanos et al. [3]; Zerva, [4]; 
Rezaeian and Der Kiureghian [5]; Cacciola and Deodatis [6]; Cacciola and Zentner [7], Cacciola et al. [8]; Wang et al [9]). It has to be emphasized, that those approaches currently proposed in the literature focus on the modelling of the free field ground motion, hence, without considering the influence of the urban environment. However, during an earthquake, a vibrating building emanates waves travelling through the ground over large distances. In the urban environment, the presence of several buildings generates the occurrence of multiple interactions that are generally referred to as seismic site-city interaction. Numerical studies on site-city interaction (see e.g. Clouteau and Aubry, [10], Kham et al., [11], Isbililiroglu et al. [12], Wirgin [13] ), showed that the presence of buildings modifies significantly the energy of the seismic waves in the underlying soil layers resulting in decrement of the ground motion energy in some areas and increment in others. Therefore, the consequent ground-motion acceleration at the free-field currently used for designing civil engineering structures can be significantly different from the predicted one inside the urban area. Several methods have been used to take into account the modification of the ground motion in the urban environment in the last two-decades. Guéguen et al. [14] showed the effect of the city can be accounted for by modelling the structures as simple oscillators. Tsogka and Wirgin [15] used homogenized blocks to study the seismic response in an idealized city. A homogenization method has been used also by Boutin and Roussillon [16] to determine the multiple interactions between buildings. Groby et al. [17] studied the seismic response of idealized 2D cities using a continuum viscoelastic medium. Ghergu and Ionescu [18] studied the collective behavior of the buildings in a city like environment through a partial differential equation coupled with an ordinary differential equation through a special class of boundary conditions. More recently Isbililiroglu et al. [12] used a finite element approach using parallel-computing code to simulate the ground motion during the 1994 Northridge earthquake and taking into account the coupled responses of multiple simplified building models located within the San Fernando Valley. The 
role of basing shapes and city density in the site-city interaction effect on the ground motion characteristics has been studied by Sahar et al. [19]. Wirgin [13] focused on energy conservation and distribution within different component of a city modelling an idealized city as: i) an additional geological layer on top of the soil layer and ii) a periodic distribution of low aspect-ratio blocks.

It has to be emphasized that no simple mathematical models and/or closed form solutions are nowadays available for the earthquake engineering community to be incorporated in a design process accounting for the urban effect in the representation of the seismic action. Moved from this need, this paper try to bridge this gap presenting a novel ground motion stochastic model for urban environment. The proposed model aims to couple the traditional ground motion stochastic models defined at the free field and analytical attenuation law models to consider the impact of a vibrating structure on the surrounding free field ground motion. A closed form solution is also proposed to model the ground motion in proximity of vibrating buildings with shallow foundations. Verification of the proposed model is carried out by the comparison of the results of power spectral density functions determined by the proposed closed form solutions and those determined numerically in a pertinent finite element model. Furthermore, parametric studies on the modification of $50 \%$ fractile of the peak ground motion acceleration due to the presence of vibrating buildings are undertaken. Finally, a simple case study is also presented as an application to show the improvement of the prediction of the peak response determined by the use of the proposed ground motion model against the traditional approach based on the free field model.

\section{Problem position}

Consider the 2D idealized portion of a city depicted in Figure 1 undergoing ground motion vibration modelled as zero mean Gaussian stationary vector process at the bedrock, $\mathbf{U}_{\mathrm{b}}$ fully 
defined by the knowledge of the power spectral density matrix $\mathbf{G}_{\mathrm{ub}}(\omega)$. Let assume for simplicity sake the structures and soil behaving linearly.

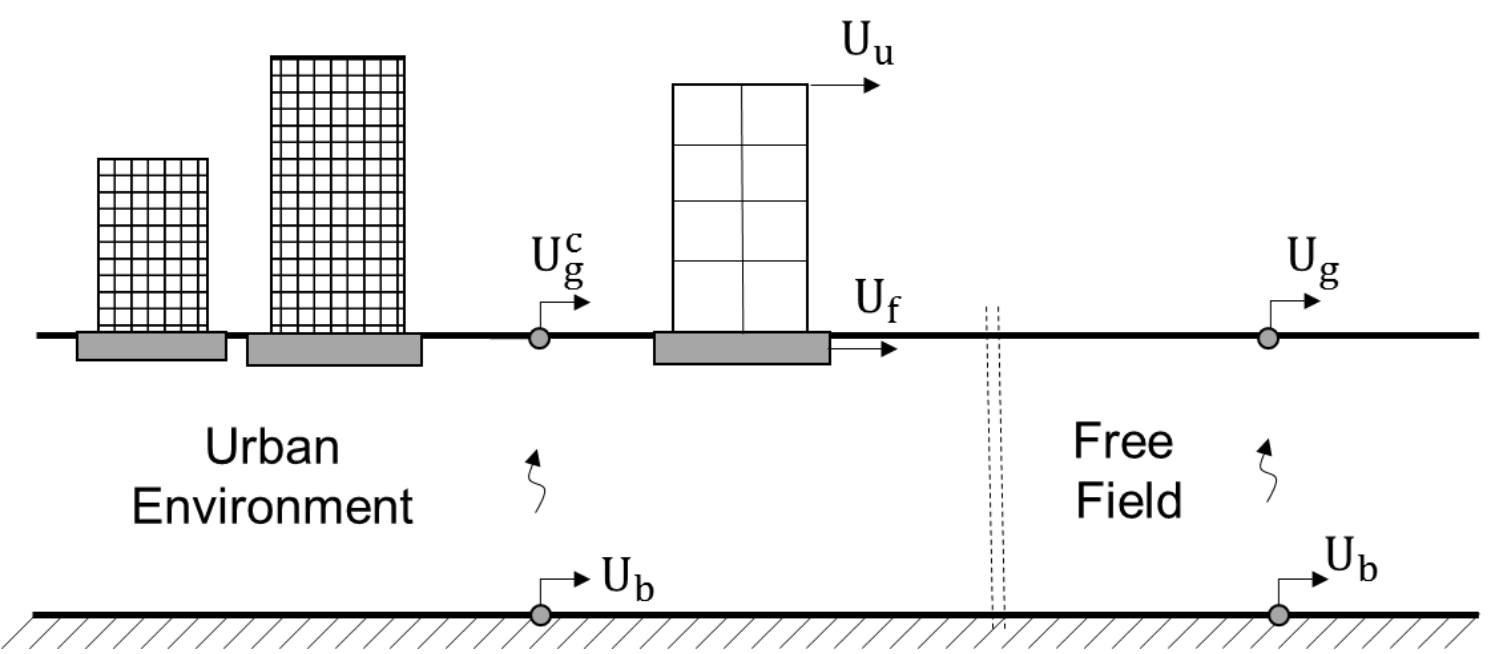

Figure 1 Sketch of an urban environment under ground motion

Under the above hypothesis the dynamic motion of the coupled urban system (after a pertinent FE discretization) is governed by the following equation in terms of absolute displacements in the frequency domain

$$
\mathbf{M} \ddot{\mathbf{U}}(\omega)+\widetilde{\mathbf{K}}(\omega) \mathbf{U}(\omega)=\widetilde{\mathbf{K}}(\omega) \mathbf{T} \mathbf{U}_{\mathrm{b}}(\omega)
$$

where $\mathbf{M}$ and $\widetilde{\mathbf{K}}(\omega)$ are the $n \times n$ mass and complex stiffness matrix of the coupled system, $\mathbf{U}$ is the vector listing the displacements of the $n$ degrees of freedom and $\mathbf{T}$ is the frequencyindependent matrix given by

$$
\mathbf{T}=-\operatorname{Re}\{\widetilde{\mathbf{K}}(\omega)\}^{-1} \mathbf{k}_{\mathrm{b}}
$$

with $\mathbf{k}_{\mathbf{b}}$ is the matrix of order $n \times n_{b}$ ( $n_{b}=$ number of degrees of freedom at the bedrock) accounting for the forces induced in the soil due a unitary displacement of each individual joint of the bedrock while the others are imposed to be zero.

Eq. (1) can be also written in expanded form as follow (see Figure 1) 


$$
\begin{aligned}
& {\left[\begin{array}{ccc}
\mathbf{M}_{\mathrm{u}} & 0 & 0 \\
0 & \mathbf{M}_{\mathrm{f}} & 0 \\
0 & 0 & \mathbf{M}_{\mathrm{s}}
\end{array}\right]\left[\begin{array}{c}
\ddot{\mathbf{U}}_{\mathrm{u}}(\omega) \\
\ddot{\mathbf{U}}_{\mathrm{f}}(\omega) \\
\ddot{\mathbf{U}}_{\mathrm{g}}^{\mathrm{c}}(\omega)
\end{array}\right]+\left[\begin{array}{ccc}
\widetilde{\mathbf{K}}_{\mathrm{u}}(\omega) & \widetilde{\mathbf{K}}_{\mathrm{u}, \mathrm{f}}(\omega) & 0 \\
\widetilde{\mathbf{K}}_{\mathrm{f}, \mathrm{u}}(\omega) & \widetilde{\mathbf{K}}_{\mathrm{f}}(\omega) & \widetilde{\mathbf{K}}_{\mathrm{s}, \mathrm{f}}(\omega) \\
0 & \widetilde{\mathbf{K}}_{\mathrm{f}, \mathrm{s}}(\omega) & \widetilde{\mathbf{K}}_{\mathrm{s}}(\omega)
\end{array}\right]\left[\begin{array}{l}
\mathbf{U}_{\mathrm{u}}(\omega) \\
\mathbf{U}_{\mathrm{f}}(\omega) \\
\mathbf{U}_{\mathrm{g}}^{\mathrm{c}}(\omega)
\end{array}\right]=} \\
& {\left[\begin{array}{ccc}
\widetilde{\mathbf{K}}_{\mathrm{u}}(\omega) & \widetilde{\mathbf{K}}_{\mathrm{u}, \mathrm{f}}(\omega) & 0 \\
\widetilde{\mathbf{K}}_{\mathrm{f}, \mathrm{u}}(\omega) & \widetilde{\mathbf{K}}_{\mathrm{f}}(\omega) & \widetilde{\mathbf{K}}_{\mathrm{s}, \mathrm{f}}(\omega) \\
0 & \widetilde{\mathbf{K}}_{\mathrm{f}, \mathrm{s}}(\omega) & \widetilde{\mathbf{K}}_{\mathrm{s}}(\omega)
\end{array}\right] \mathbf{T U}_{\mathrm{b}}(\omega)}
\end{aligned}
$$

where $\mathbf{M}_{\mathrm{j}}$, and $\mathbf{K}_{\mathbf{j}}(\omega)$ are the mass and the complex stiffness submatrices in which the index $\mathrm{j}=\mathrm{u}, \mathrm{f}, \mathrm{s}$ is used for indicating the buildings superstructure in the urban environment, the building foundations and the soil, respectively. The vector $\mathbf{U}_{\mathrm{j}}$ for $\mathrm{j}=\mathrm{u}, \mathrm{f}, \mathrm{s}$ lists the displacements degrees of freedom. Note that Eq. (3) highlights the unknown vector $\ddot{\mathbf{U}}_{\mathrm{g}}^{\mathrm{c}}$ that represents the ground motion of the soil deposit within the urban environment. The ground motion at a specific location within the urban environment can be, therefore, readily extracted by the response power spectral density matrix given by the following equation

$$
\mathbf{G}_{\mathbf{U}}(\omega)=\mathbf{H}(\omega) \mathbf{G}_{\mathrm{U}_{\mathrm{b}}}(\omega) \mathbf{H}^{*}(\omega)
$$

where the asterisk in Eq. (4) stands for transpose complex conjugate, and the matrix $\mathbf{H}(\omega)$ is given by

$$
\mathbf{H}(\omega)=\left(\widetilde{\mathbf{K}}(\omega)-\omega^{2} \mathbf{M}\right)^{-1} \widetilde{\mathbf{K}}(\omega) \mathbf{T}
$$

From Eq. (4) elements of the response power spectral density matrix $\mathbf{G}_{\mathbf{U}}(\omega)$, and in particular the elements pertinent to the degrees of freedom of the soil at the surface, are in general function of both the soil and the structures within the urban environment. The seismic wave field on the surface is, therefore, affected by the presence of the buildings that can be interpreted as vibrating obstacles, inducing scattering to the ground motion waves and will be different from the traditionally used free field ground motion that neglects the presence of vibrating structures. In the case of ground motion at the bedrock modelled as monocorrelated Gaussian stochastic process Eq. (1) is reduced to 


$$
\mathbf{M} \ddot{\mathbf{U}}(\omega)+\widetilde{\mathbf{K}}(\omega) \mathbf{U}(\omega)=\widetilde{\mathbf{K}}(\omega) \tau U_{\mathrm{b}}(\omega)
$$

where $\boldsymbol{\tau}$ is the incidence vector. As a consequence the response power spectral density matrix is given by

$$
\mathbf{G}_{\mathbf{U}}(\omega)=\mathbf{H}(\omega) \mathbf{H}^{*}(\omega) \mathrm{G}_{\mathrm{U}_{\mathrm{b}}}(\omega)
$$

where $G_{U_{b}}(\omega)$ is the power spectral density function of the ground motion at the bedrock. Although the approach of modelling a large portion of a city might be attractive as it faces directly the problem to determine the ground motion in the urban environment by extracting the pertinent elements from the response matrix, from a practical point of view it is unfeasible due its computational demand and for the unavoidable epistemic uncertainties involved in the model. Therefore, an alternative approach is proposed in this paper and it is presented in the following sections.

\section{Proposed solution in proximity of a vibrating building}

In order to cope with the challenging task to determine the ground motion within an urban environment, in this section the simplest case considering the influence of a single vibrating structure on the nearby free-field ground motion (Figure 2) is addressed first. Specifically, the aim is to determine a reliable ground motion model $\mathrm{U}_{\mathrm{g}}^{\mathrm{c}}$ able to accounting for the wave field (at a distance d) radiated by the structure undergoing ground motion excitation modelled as a stochastic process $\mathrm{U}_{\mathrm{b}}$ at the bedrock. 


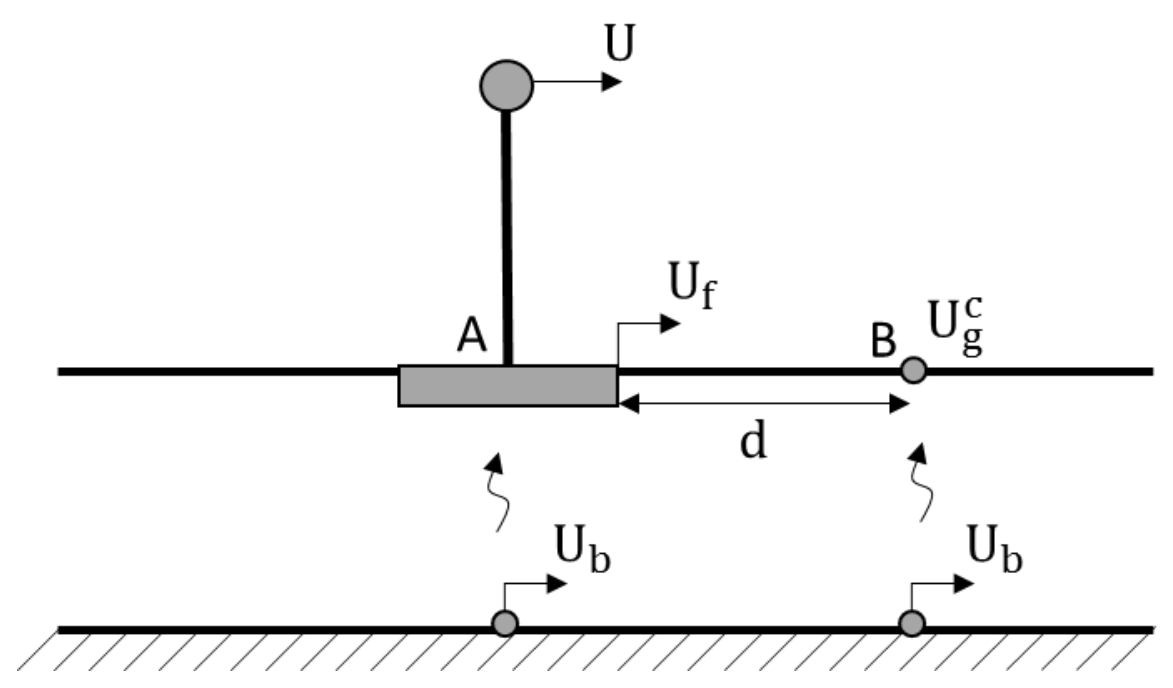

Figure 2 Seismic wave field surrounding a building induced by bedrock excitation

The proposed approach requires three key steps: i) the solution of dynamic response of the soilstructure interaction system; ii) the evaluation of the radiated wave field generated by the vibrating structure and iii) the evaluation of the ground motion in the proximity of a vibrating structure as a superposition of the free field ground motion and the radiated wave field. In this regard, consider first the discrete system illustrated in Figure 3. The model comprises a SDOF superstructure characterized by structural stiffness, $\tilde{\mathrm{k}}_{\text {str }}$, a mass at the top of the superstructure, $m_{\text {str }}$, and a foundation-soil system, fully defined by stiffness, $\tilde{\mathrm{k}}_{\mathrm{SSI}}$ for capturing soil-structure interaction effects and mass at foundation level, $\mathrm{m}_{\mathrm{f}}$. Only the horizontal absolute components of the structure and foundation displacements, $U$ and $U_{f}$, respectively, are considered. Therefore, the model likely represents one of the simplest mechanical models able to capture soil-structure interaction effects (alternative simplified models can be clearly adopted such us those proposed by Wolf [20], and Gueguen et al [14]). 


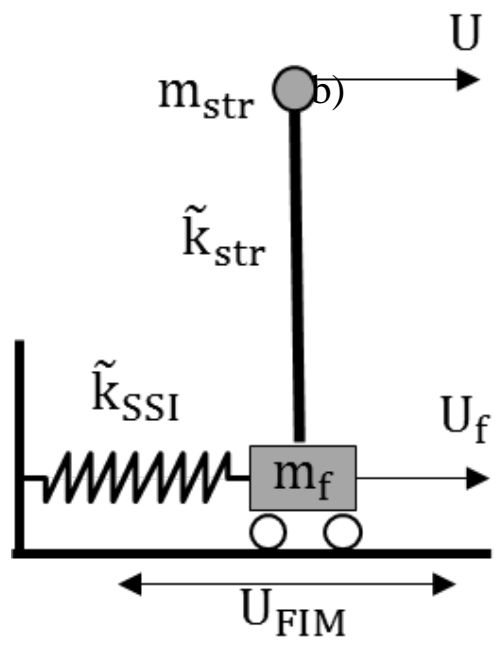

Figure 3 Structural discrete model by considering soil-structure interaction effects

The equation governing the motion of the system in terms of absolute displacements in the frequency domain reads

$$
\left(\widetilde{\mathbf{K}}(\omega)-\omega^{2} \mathbf{M}\right) \mathbf{U}(\omega)=\widetilde{\mathbf{K}}(\omega) \boldsymbol{\tau} \mathrm{U}_{\mathrm{FIM}}(\omega)
$$

Where $\mathrm{U}_{\mathrm{FIM}}(\omega)$ is the input motion at the base of the foundation, usually referred to as foundation input motion, namely the motion of the massless foundation under seismic loading. Therefore, from Eq. 4 the solution in its expanded form is given by

$$
\left[\begin{array}{c}
\mathrm{U}(\omega) \\
\mathrm{U}_{\mathrm{f}}(\omega)
\end{array}\right]=\left(\left[\begin{array}{cc}
\tilde{\mathrm{k}}_{\mathrm{str}} & -\tilde{\mathrm{k}}_{\mathrm{str}} \\
-\tilde{\mathrm{k}}_{\mathrm{str}} & \tilde{\mathrm{k}}_{\mathrm{str}}+\tilde{\mathrm{k}}_{\mathrm{SSI}}(\omega)
\end{array}\right]-\omega^{2}\left[\begin{array}{cc}
\mathrm{m}_{\mathrm{str}} & 0 \\
0 & \mathrm{~m}_{\mathrm{f}}
\end{array}\right]\right)^{-1}\left[\begin{array}{c}
0 \\
\tilde{\mathrm{k}}_{\mathrm{SSI}}(\omega)
\end{array}\right] \mathrm{U}_{\mathrm{FIM}}(\omega)
$$

Whereas the hypothesis of hysteretic damping is retained, i.e. $\tilde{\mathrm{k}}_{\mathrm{str}}=\mathrm{k}_{\mathrm{str}}(1+i \eta), i$ is the imaginary unit and $\eta$ is the loss factor. Furthermore, the dependence of $\tilde{\mathrm{k}}_{\mathrm{SSI}}$ from the circular frequency $\omega$ is hereinafter omitted for simplicity sake and determined through a static approach, without affecting the generality of the formulation. Therefore, the frequency transfer function of the foundation displacement, $\mathrm{H}_{\mathrm{f}}(\omega)$, defined as the ratio between the foundation displacement, $U_{f}(\omega)$, and the foundation input motion, $U_{\text {FIM }}(\omega)$, is readily derived as follows:

$$
\mathrm{H}_{\mathrm{f}}(\omega)=\frac{\mathrm{U}_{\mathrm{f}}(\omega)}{\mathrm{U}_{\mathrm{FIM}}(\omega)}=\frac{\widetilde{\omega}_{\mathrm{f}}^{2}\left(\omega^{2}-\widetilde{\omega}_{0}^{2}\right)}{\left(\widetilde{\omega}_{0}^{2}-\omega^{2}\right)\left(\omega^{2}-\widetilde{\omega}_{\mathrm{f}}^{2}\right)+\omega^{2}\left(\widetilde{\mathrm{K}}_{\mathrm{str}} / \mathrm{m}_{\mathrm{f}}\right)}
$$


where

$$
\omega_{0}^{2}=\left(\frac{k_{\mathrm{str}}}{m_{\mathrm{str}}}\right)
$$

is the squared circular natural frequency of the fixed base SDOF superstructure and,

$$
\omega_{\mathrm{f}}^{2}=\left(\frac{k_{\mathrm{SSI}}}{m_{\mathrm{f}}}\right)
$$

is the squared circular natural frequency of the soil-foundation system.

Once $U_{f}(\omega)$ is determined, the wave field radiated by the vibrating foundation needs to be determined. It is noted that the radiated wave field depends form the geometry of the foundation and different strategies (see e.g. Hisada [21, 22]), mostly numerical, can be adopted in this regard. With the aim of developing an analytical model, in this paper, the foundation of the structure, assumed shallow, is approximated by an equivalent cylindrical shape. As a consequence, the asymptotic cylindrical waves propagating from a cylinder subjected to a harmonic signal can be determined through the attenuation function $\alpha(d, \omega)$, (see e.g. Morse and Ingard, [23]) given by:

$$
\alpha(d, \omega)=\sqrt{\frac{a}{d}} \exp \left(-\frac{\eta_{g} \omega d}{V_{L a}}\right) \exp \left[-i \omega\left(\frac{d}{V_{L a}}\right)\right] \quad \forall d \geq a
$$

where $\mathrm{a}$ is the equivalent radius of the foundation, $\mathrm{d}$ is the distance between a selected point on the ground surface and the border of the foundation and $V_{\mathrm{La}}=\left(3.4 \mathrm{~V}_{\mathrm{s}}\right) /[\pi(1-v)]$ is the Lysmer's analogue velocity and $v$ is the soil Poisson ratio (Dobry and Gazetas, [24]) and $\eta_{g}$ is the soil loss factor. Therefore the wave field radiated by the vibrating foundation is given by

$$
U_{g}^{f}(d, \omega)=\alpha(d, \omega) U_{f}^{r}(\omega)=\sqrt{\frac{a}{d}} \exp \left(-\frac{\eta \omega d}{V_{L a}}\right) \exp \left[-i \omega\left(\frac{d}{V_{L a}}\right)\right] U_{f}^{r}(\omega) \quad \forall d \geq a
$$

where $U_{f}^{r}(\omega)=U_{f}(\omega)-U_{\text {FIM }}(\omega)$. Finally, at ground level in proximity of the vibrating structure at a certain distance $d, U_{g}^{c}(d, \omega)$, induced by the motion of the foundation $U_{f}(\omega)$ is 
determined as a superposition of the two effects, namely: the free field motion, $U_{g}(\omega)$, and the radiated motion $U_{g}^{f}(d, \omega)$, that is

$$
U_{g}^{c}(d, \omega)=U_{g}(\omega)+U_{g}^{f}(d, \omega)
$$

or equivalently:

$$
\mathrm{U}_{\mathrm{g}}^{\mathrm{c}}(\mathrm{d}, \omega)=\mathrm{U}_{\mathrm{g}}(\omega)+\alpha(\mathrm{d}, \omega)\left(\mathrm{U}_{\mathrm{f}}(\omega)-\mathrm{U}_{\mathrm{FIM}}(\omega)\right)
$$

Eqs (15) and (16) represent the ground motion in proximity of a vibrating structure at the soil surface and require the knowledge of the free field ground motion (in absence of buildings) and the foundation response.

\subsection{Gaussian bedrock ground motion process}

Under the hypothesis of stationary zero mean Gaussian input the power spectral density function of the ground motion, $G_{U_{g}^{c}}(d, \omega)$, in proximity (i.e. at a distance d) of a vibrating structure can be derived readily from Eq. (15), that is :

$$
G_{U_{g}^{c}}(d, \omega)=G_{U_{g}}(\omega)+G_{U_{g}^{f}}(d, \omega)+G_{U_{g} U_{g}^{f}}(d, \omega)+G_{U_{g}^{f} U_{g}}(d, \omega)
$$

where $G_{U_{g}}(\omega)$ is the power spectral density function of the free field ground motion, $G_{U_{g}^{f}}(d, \omega)$ is the power spectral density function of the radiated wave field, while $G_{U_{g} U_{g}^{f}}(d, \omega)$ and $\mathrm{G}_{\mathrm{Ug}_{\mathrm{g}}^{\mathrm{f}}}(\mathrm{d}, \omega)$ are the cross spectra.

Note that, the foundation input motion, $\mathrm{U}_{\mathrm{FIM}}(\omega)$ (see Eqs 8 and 9) for normalized frequencies, $\frac{\omega \mathrm{r}}{\mathrm{V}_{\mathrm{s}}}<0.2 \sim 0.25$ or for footing foundations (Jennings and J. Bielak, [25], Bielak, [26], Wolf, [20], Carbonari et al., [27]), can be approximated by the free field motion, $\mathrm{U}_{\mathrm{g}}(\omega)$, i.e. $\mathrm{U}_{\mathrm{FIM}}(\omega) \cong \mathrm{U}_{\mathrm{g}}(\omega)$. Therefore, under this hypothesis it can be shown that free field ground motion and radiated wave field are fully coherent (i.e. $\left.\gamma_{U_{g} U_{g}^{f}}(d, \omega)=\gamma_{U_{g}^{f} U_{g}}(d, \omega)=1\right)$. 
Therefore, after simple algebra the proposed ground motion acceleration power spectral density at a distance $\mathrm{d}$ from the vibrating structure can be determined in the following closed form:

$$
\mathrm{G}_{\ddot{\mathrm{Ug}} \mathrm{g}}^{\mathrm{c}}(\mathrm{S}, \omega)=\left|1+\alpha(\mathrm{d}, \omega) \mathrm{H}_{\mathrm{f}}^{\mathrm{r}}(\omega)\right|^{2} \mathrm{G}_{\ddot{U}_{\mathrm{g}}}(\omega)
$$

where $\mathrm{H}_{\mathrm{f}}^{\mathrm{r}}(\omega)$ is the transfer function of the foundation in relative displacement, defined as $\mathrm{H}_{\mathrm{f}}^{\mathrm{r}}(\omega)=\mathrm{H}_{\mathrm{f}}(\omega)-1$ and $\mathrm{G}_{\ddot{U}_{\mathrm{g}}}(\omega)$ is the ground motion acceleration power spectral density at the free field that can be determined using traditional models proposed in literature (e.g. Clough and Penzien, [28]), or by response-spectrum-compatible models (e.g., see Cacciola [29], and Giaralis and Spanos, [30]). The power spectral density function defined by Eq. (18) defines the ground motion in the proximity of a vibrating structure through a Gaussian stationary model. The more the distance $d$ increases (and $\alpha(d, \omega)$ decreases) the smaller will be clearly the influence of the vibrating structure to the earthquake induced ground motion so to converge to the traditional free field ground motion model.

Furthermore, by assuming the ground motion at the bedrock modelled as a Gaussian white noise process with unilateral power spectral density $\mathrm{G}_{\mathrm{W}}$, Eq. (18) can be rewritten as

$$
G_{\ddot{U}_{g}^{c}}(d, \omega)=\left|1+\alpha(d, \omega) H_{f}^{r}(\omega)\right|^{2}\left|H_{\text {soil }}(\omega)\right|^{2} G_{W}
$$

where $H_{\text {soil }}(\omega)$ is the transfer function of the soil profile that for one-dimensional vertical wave propagation and rigid bedrock is given by Kramer [31]:

$$
\left|H_{\text {soil }}(\omega)\right|=\frac{1}{\sqrt{\cos ^{2}\left(\frac{\omega h}{V_{\mathrm{s}}}\right)+\left(\frac{\zeta g \omega h}{V_{s}}\right)^{2}}}
$$

where $\mathrm{h}$ is the depth of the soil deposit, and $\zeta_{\mathrm{g}}$ is the damping ratio of the ground. 


\subsection{Gaussian bedrock ground motion vector process}

The proposed stochastic ground motion model in the proximity of a vibrating structure is herein extended to take into account an incoherent ground motion at a different point of the free field. Let $\mathbf{U}_{\mathrm{g}}(\omega)$ the zero mean, Gaussian stationary vector process listing the free field ground motion at the points $A$ and $B$, i.e. $U_{g}^{A}(\omega)$ and $U_{g}^{B}(\omega)$, (see Figure 4), and fully defined by power spectral density matrix (see e.g. Deodatis [1]):

$$
\mathbf{G}_{U_{g}}(d, \omega)=\left[\begin{array}{cc}
G_{U_{g}}^{A A}(\omega) & G_{U_{g}}^{A B}(d, \omega) \\
G_{U_{g}}^{B A}(d, \omega) & G_{U_{g}}^{B B}(\omega)
\end{array}\right]
$$

where $\mathrm{G}_{\mathrm{U}_{\mathrm{g}}}^{\mathrm{ii}}(\omega)(i=A, B)$ is the unilateral power spectral density function of the ground motion $\mathrm{U}_{\mathrm{g}}^{\mathrm{i}}(\omega)(i=A, B)$ and $\mathrm{G}_{\mathrm{U}_{\mathrm{g}}}^{\mathrm{ij}}(\omega)=\Gamma_{i j}(\mathrm{~d}, \omega) \sqrt{\mathrm{G}_{\mathrm{U}_{\mathrm{g}}}^{\mathrm{ii}}(\omega) \mathrm{G}_{\mathrm{U}_{\mathrm{g}}}^{\mathrm{jj}}(\omega)}(i, j=A, B ; i \neq j)$ are the cross spectral density functions, with $\Gamma_{i j}(\mathrm{~d}, \omega)$ the coherency function that is also in general function of the distance between the two points A e B due to the wave passage effect (see e.g. Deodatis [1]; Zerva [4]).
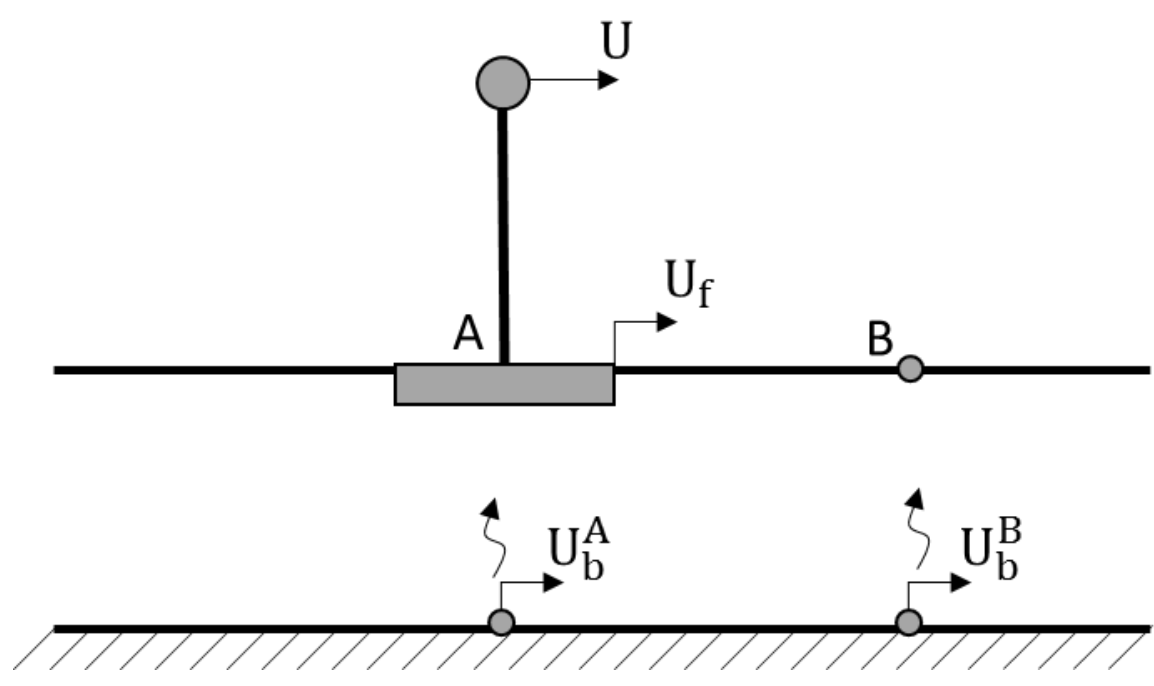

Figure 4 Seismic wavefield surrounding a building induced by incoherent bedrock excitation 
Let's consider now a vibrating structure located at point $\mathrm{A}$, and let $\mathrm{d}$ the distance between $\mathrm{A}$ and B. Under this hypothesis the modified ground motion in B assumes the following form (see Eq. 15)

$$
\mathrm{U}_{\mathrm{g}}^{\mathrm{c}, \mathrm{B}}(\mathrm{d}, \omega)=\mathrm{U}_{\mathrm{g}}^{\mathrm{B}}(\omega)+\alpha(\mathrm{d}, \omega)\left(\mathrm{U}_{\mathrm{f}}(\omega)-\mathrm{U}_{\mathrm{g}}^{\mathrm{A}}(\omega)\right)
$$

with $U_{f}(\omega)$, displacement of the foundation located in $A$,

$$
\mathrm{U}_{\mathrm{f}}(\omega)=\mathrm{H}_{\mathrm{f}}(\omega) \mathrm{U}_{\mathrm{g}}^{\mathrm{A}}(\omega)
$$

Eq. (22) can be conveniently written in matrix form in the following way

$$
\mathrm{U}_{\mathrm{g}}^{\mathrm{c}, \mathrm{B}}(\mathrm{d}, \omega)=\mathbf{H}_{\alpha}(d, \omega) \mathbf{U}_{\mathrm{g}}(\omega)
$$

Where

$$
\mathbf{H}_{\alpha}(\mathrm{d}, \omega)=\left[\alpha(\mathrm{d}, \omega) \mathrm{H}_{\mathrm{f}}^{\mathrm{r}}(\omega) \quad 1\right]
$$

After simple algebra the power spectral density matrix of the ground motion process at a selected point in the urban environment $\mathrm{G}_{\ddot{U}_{\mathrm{g}}^{\mathrm{c}}}(\mathrm{d}, \omega)$ is given by the following equation

$$
G_{\ddot{U}_{g}^{c}}(d, \omega)=\mathbf{H}_{\alpha}(d, \omega) \mathbf{G}_{\ddot{U}_{g}}(d, \omega) \mathbf{H}_{\alpha}^{*}(d, \omega)
$$

that to be used in conjunction with well know stochastic ground motion vector processes at the free field (see e.g. Deodatis [1]; Zerva [4]; Cacciola and Deodatis [6]). Note that for $\mathrm{d} \rightarrow \infty, \Gamma_{i j}(\mathrm{~d}, \omega) \rightarrow 0$ and $\mathbf{H}_{\alpha}(d, \omega)$ assumes the following form

$$
\lim _{d \rightarrow \infty} \mathbf{H}_{\alpha}(d, \omega)=\left[\begin{array}{ll}
0 & 1
\end{array}\right]
$$

Therefore,

$$
\lim _{d \rightarrow \infty} G_{\ddot{U}}(d, \omega)=G_{\ddot{U}_{g}}^{B B}(\omega)
$$

Furthermore, in the case in which the ground motion is defined at the bedrock Eq. (26) is rewritten in the following form

$$
\mathbf{G}_{\ddot{U}_{\mathrm{g}}^{\mathrm{c}}}(\mathrm{d}, \omega)=\mathbf{H}_{\alpha}(\mathrm{d}, \omega) \mathbf{H}_{\text {soil }} \mathbf{G}_{\ddot{\mathrm{U}}_{\mathrm{b}}}(\mathrm{d}, \omega) \mathbf{H}_{\text {soil }}{ }^{*}(\mathrm{~d}, \omega) \mathbf{H}_{\alpha}{ }^{*}(\mathrm{~d}, \omega)
$$


Where

$$
\mathbf{H}_{\text {soil }}=\left[\begin{array}{cc}
\mathrm{H}_{\text {soil }}^{\mathrm{A}}(\omega) & 0 \\
0 & \mathrm{H}_{\text {soil }}^{\mathrm{B}}(\omega)
\end{array}\right]
$$

and

$$
\mathbf{G}_{\ddot{U}_{b}}(d, \omega)=\left[\begin{array}{cc}
G_{\ddot{U}_{b}}^{A A}(\omega) & G_{\ddot{U}_{b}}^{A B}(d, \omega) \\
G_{\ddot{U}_{b}}^{B A}(d, \omega) & G_{\ddot{U}_{b}}^{B B}(\omega)
\end{array}\right]
$$

is the power spectral density matrix of the ground motion at the bedrock (see. e.g Der Kiureghian, [32]).

\subsection{Proposed Stochastic Ground Motion Model for the Urban Environment}

In the previous sections the influence of a vibrating individual structure on the free field ground motion has been addressed. Namely the proposed modified ground motion at the surface level is given by the superposition of two contributions: the free field ground motion and wave field radiated by the individual structures. Owing to the linearity of the problem the model is herein extended to taking account the contribution of multiple vibrating structures on the surface. Specifically, consider the case depicted in Figure 5, in which two buildings, are represented along with the relevant degrees of freedom.
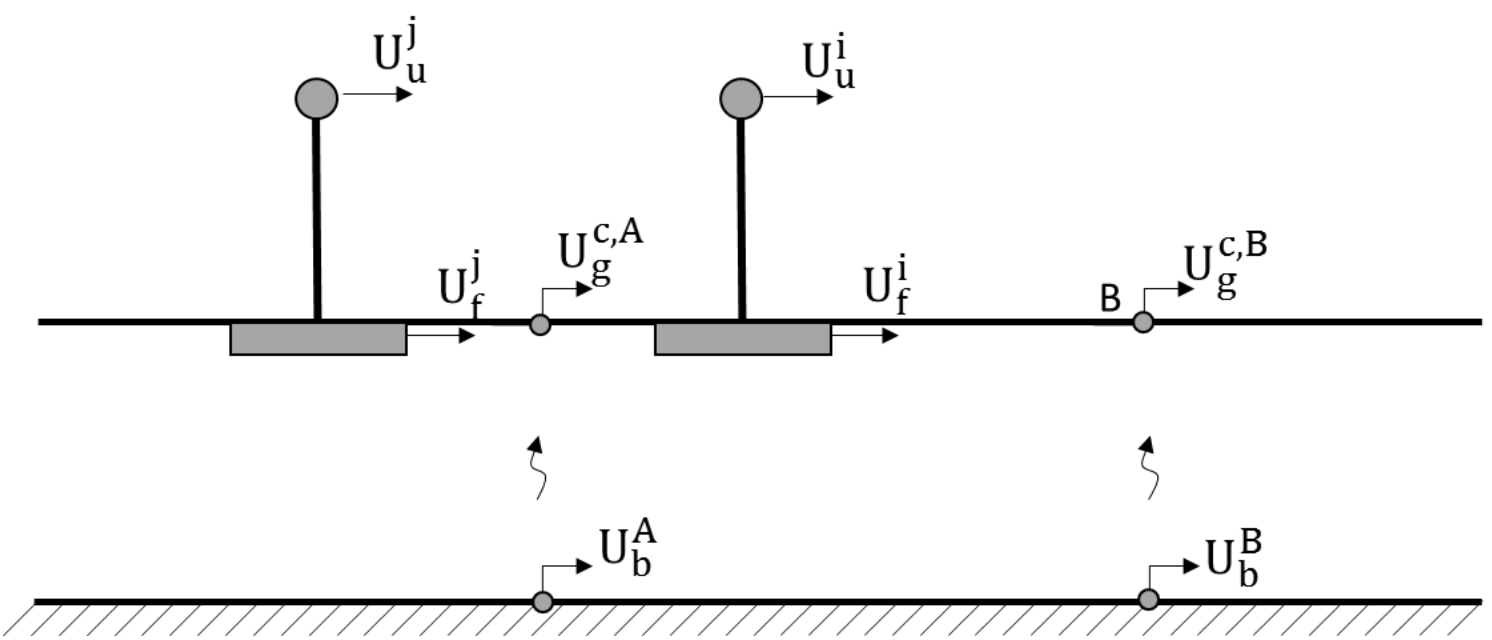

Figure 5 Seismic wave field surrounding a cluster of buildings induced by coherent or incoherent bedrock excitation 
Following Poulos's assumption (Poulos, [33], Dobry and Gazetas, [24]) only the interaction of one source and one receiver at a time is considered. Therefore, the interaction between two building foundations is neglected. This assumption leads directly to the following representation of the ground motion process at selected point within the urban environment (see Eqs. 22 and 23):

$$
\mathrm{U}_{\mathrm{g}}^{\mathrm{c}, \mathrm{k}}(\omega)=\mathrm{U}_{\mathrm{g}}^{\mathrm{k}}(\omega)+\sum_{\mathrm{i}=1}^{\mathrm{n}} \alpha_{i}\left(d_{i k}, \omega\right)\left(\mathrm{U}_{\mathrm{f}}^{\mathrm{i}}(\omega)-\mathrm{U}_{\mathrm{g}}^{\mathrm{i}}(\omega)\right) \quad \mathrm{k}=\mathrm{A}, \mathrm{B}, \ldots
$$

with $\mathrm{U}_{\mathrm{f}}^{\mathrm{k}}(\omega)$ given by

$$
\mathrm{U}_{\mathrm{f}}^{\mathrm{k}}(\omega)=\mathrm{H}_{\mathrm{f}}^{\mathrm{k}}(\omega) \mathrm{Ug}_{\mathrm{g}}^{\mathrm{k}}(\omega)
$$

where $U_{g}^{c, k}$ is the modified ground motion process at the location $k, U_{g}^{k}(\omega)$ is the free field ground motion process, $H_{f}^{k}(\omega)$ is the foundation transfer function, $U_{f}^{k}(\omega)$ is the foundation response, $\alpha_{i}\left(d_{i k}, \omega\right)$ is the attenuation function radiated by the $i$ th structure at a distance $d_{i k}$ between the foundation of the ith structure and the selected point $\mathrm{k}$, and $\mathrm{n}$ is the number of structures considered.

Therefore, Eq. (32) can be conveniently rewritten in the following matrix form

$$
\mathrm{U}_{\mathrm{g}}^{\mathrm{c}}(\omega)=\mathbf{H}_{\mathrm{c}}(\omega) \mathbf{U}_{\mathrm{g}}(\omega)
$$

where $\mathbf{H}_{\alpha}(\omega)$ is the following $(n+1) \times 1$ vector

$$
\mathbf{H}_{\alpha}(\omega)=\left[\Psi_{1}\left(d_{1 k}, \omega\right) \quad \cdots \quad \Psi_{\mathrm{n}}\left(d_{n k}, \omega\right) \quad 1\right]
$$

where $\Psi_{\mathrm{i}}\left(d_{i k}, \omega\right)=\alpha_{\mathrm{i}}\left(d_{i k}, \omega\right) \mathrm{H}_{\mathrm{f}}^{\mathrm{r}, \mathrm{i}}(\omega)$ and $\mathrm{H}_{\mathrm{f}}^{\mathrm{r}, \mathrm{i}}(\omega)=\mathrm{H}_{\mathrm{f}}^{\mathrm{i}}(\omega)-1$.

Therefore, the power spectral density function of the ground motion in the urban environment altered by the presence of $n$ structures assumes the following form

$$
G_{\ddot{U}_{g}^{c} \ddot{U}_{g}^{c}}(\omega)=\mathbf{H}_{\alpha}(\omega) \mathbf{G}_{\ddot{u}_{g}} \ddot{u}_{g}(\omega) \mathbf{H}_{\alpha}(\omega)^{*}
$$

Clearly the $n$ structures to include model defined by Eq. (35) are only the structures nearby the selected point. The preliminary study of the attenuation functions will determine the size of the 
problem. After simple algebra it can be shown that for fully coherent Gaussian stationary ground motion process the power spectral density function of the ground motion in the selected point $k$ on the soil surface is given by

$$
\mathrm{G}_{\ddot{\mathrm{U}}_{\mathrm{g}}^{\mathrm{C}} \ddot{\mathrm{U}}_{\mathrm{g}}^{\mathrm{c}}}(\omega)=\left|1+\sum_{\mathrm{i}=1}^{\mathrm{n}} \Psi^{\mathrm{i}}\left(d_{i k}, \omega\right)\right|^{2} \mathrm{G}_{\ddot{U}_{\mathrm{g}} \ddot{U}_{\mathrm{g}}}(\omega)
$$

That can be readily applied in any stochastic analysis.

\section{Stochastic seismic response including soil-structure interaction}

In this section for the sake of completeness the stochastic response of a quiescent structure including soil-structure interaction effects, under the proposed ground motion model is provided. Specifically, the motion governing the response of the m-dof linear behaving structure undergoing monocorrelated ground motion base excitation is written in term of absolute displacements:

$$
\left(\widetilde{\mathbf{K}}(\omega)-\omega^{2} \mathbf{M}\right) \mathbf{U}(\omega)=\widetilde{\mathbf{K}}(\omega) \boldsymbol{\tau} \mathrm{U}_{\mathrm{g}}^{c}(\omega)
$$

or in expanded form

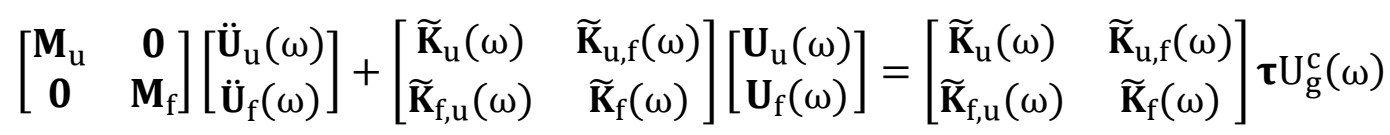

where the proposed ground motion model, $\mathrm{U}_{\mathrm{g}}^{\mathrm{c}}(\omega)$, is adopted in lieu of the traditional free field ground motion model $U_{g}(\omega)$. The power spectral density matrix of the response is readily derived:

$$
\mathbf{G}_{\mathbf{U}}(\omega)=\mathbf{H}(\omega) \mathbf{H}^{*}(\omega) \mathrm{G}_{\mathrm{Ug}_{\mathrm{g}}^{c}}(\omega)
$$

with $\mathbf{H}(\omega)$ given by

$$
\mathbf{H}(\omega)=\left(\widetilde{\mathbf{K}}(\omega)-\omega^{2} \mathbf{M}\right)^{-1} \widetilde{\mathbf{K}}(\omega) \boldsymbol{\tau}
$$


Finally, the fractile of order $p$ of the selected peak response parameter $U_{j}^{\mathrm{r}}(\omega)$ (e.g. $j$ th relative displacements) is obtained by means of the first crossing problem (see e.g. Vanmarcke and Gasparini [34]):

$$
\mathrm{X}_{\mathrm{U}_{j}^{r}}\left(\mathrm{~T}_{\mathrm{W}}, \mathrm{p}\right)=\eta_{\mathrm{U}_{j}^{r}}\left(\mathrm{~T}_{\mathrm{W}}, \mathrm{p}, \lambda_{0, \mathrm{U}_{j}^{\mathrm{r}}}, \lambda_{1, \mathrm{U}_{j}^{\mathrm{r}}}, \lambda_{2, \mathrm{U}_{j}^{\mathrm{r}}}\right) \sqrt{\lambda_{0, \mathrm{U}_{j}^{\mathrm{r}}}}
$$

where $\mathrm{T}_{\mathrm{W}}$ is the time observing window; $\lambda_{i, U}(i=0,1,2)$ are the $i$ th-order response spectral moments and $\eta_{\mathrm{U}_{j}^{\mathrm{r}}}$ is the peak factor given by

$$
\eta_{\mathrm{U}_{j}^{r}}=\sqrt{2 \ln \left\{2 N_{\mathrm{U}_{j}^{\mathrm{r}}}\left[1-\exp \left[-\delta_{\mathrm{U}_{j}^{\mathrm{r}}}^{1.2} \sqrt{\pi \ln \left(2 N_{\mathrm{U}_{j}^{\mathrm{r}}}\right)}\right]\right]\right\}}
$$

with

$$
N_{\mathrm{U}_{j}^{\mathrm{r}}}=\frac{T_{S}}{-2 \pi \ln p} \sqrt{\frac{\lambda_{2, \mathrm{U}_{j}^{\mathrm{r}}}}{\lambda_{0, \mathrm{U}_{j}^{\mathrm{r}}}}}
$$

and

$$
\delta_{\mathrm{U}_{j}^{\mathrm{r}}}=\sqrt{1-\frac{\lambda_{1, \mathrm{U}_{j}^{\mathrm{r}}}^{2}}{\lambda_{0, \mathrm{U}_{j}^{\mathrm{r}} \lambda_{2, \mathrm{U}_{j}^{\mathrm{r}}}}}}
$$

where the response spectral moments $\lambda_{i, \mathrm{U}_{j}^{r}}$ are given by the following equation:

$$
\lambda_{i, \mathrm{U}_{j}^{r}}=\int_{0}^{+\infty} \omega^{i} \mathrm{G}_{\mathrm{U}_{j}^{\mathrm{r}}}(\omega) d \omega
$$

with $G_{U_{j}^{r}}(\omega)$ power spectral density function of the selected relative displacements. Note that in the case in which soil-structure interaction is accounted for the solution is sought in terms of absolute displacements, so to include the foundation degrees of freedom. Furthermore, the formulation in the frequency domain allows to take into account for the dependence from the frequency of the soil stiffness embedded in the matrix $\widetilde{\mathbf{K}}_{\mathrm{f}}(\omega)$. In the following section the proposed model of ground motion in the urban environment is applied and compared with pertinent Monte Carlo studies. 


\section{Numerical results}

\subsection{Parametric analysis}

In this section the proposed ground motion model is applied. The simplest scenario of a SDoF superstructure vibrating under ground motion is considered first. The structure is defined by the stiffness, $k_{s t r}$, mass, $m_{s t r}$ and it is founded on an embedded foundation of $1 \mathrm{~m}$-deep and $2 \mathrm{~m}$-wide, characterized by soil-foundation stiffness, $k_{\mathrm{SSI}}$, and foundation mass, $m_{\mathrm{f}}$. The soil domain is characterized by average shear wave velocity, $\mathrm{V}_{\mathrm{s}}=400 \mathrm{~m} / \mathrm{s}$, soil damping $\eta_{g}=$ 0.1 and bedrock at 30m depth. The ground motion at the bedrock is modelled as zero mean Gaussian white noise process with $\mathrm{G}_{W}=0.04 \mathrm{~m}^{2} \mathrm{~s}^{-3}$.

In order to study the effect of the wave field radiated by the SDoF superstructure on the free field ground motion, the $50 \%$ fractile of the of peak ground acceleration of the wave fields is obtained via the first crossing problem (see e.g. Vanmarcke and Gasparini [34]). In this regard, the comparison is performed in term of the ratio $\Delta$ of the $50 \%$ fractiles of the peak ground acceleration determined through of the proposed model and the free field ground motion, that is

$$
\Delta(s, \mathrm{~T})=\frac{X_{\ddot{\mathrm{U}}_{\mathrm{g}}^{\mathrm{c}}}(\mathrm{T}, \mathrm{s})}{\mathrm{X}_{\ddot{\mathrm{U}}_{\mathrm{g}}}(\mathrm{s})}
$$

where $\mathrm{s}$ is spatial coordinate on the soil surface, $\mathrm{T}$ is the fundamental period of the vibrating structure, $X_{\ddot{U}_{\mathrm{g}}^{\mathrm{c}}}(\mathrm{T}, \mathrm{s})$ and $\mathrm{X}_{\ddot{U}_{\mathrm{g}}}(\mathrm{s})$ are the $50 \%$ fractile (with time observing window $\mathrm{T}_{W}=10 \mathrm{~s}$ ) of the peak ground motion process determined by using the proposed ground motion model (Eq. 18) and the traditional free field ground motion

$$
\mathrm{G}_{\ddot{U}_{\mathrm{g}}}(\omega)=\left|\mathrm{H}_{\text {soil }}(\omega)\right|^{2} \mathrm{G}_{W}
$$


with $\left|\mathrm{H}_{\text {soil }}(\omega)\right|$ defined in Eq. (20)), $\mathrm{s}$ is spatial coordinate on the soil surface and $\mathrm{T}$ is the fundamental period of the vibrating structure.

In Figure 6a, $\Delta(s, \mathrm{~T})$ is obtained by considering a structure with mass, $m_{\mathrm{str}}=350000 \mathrm{~kg}$, $m_{\mathrm{f}}=15400 \mathrm{~kg} ;$ structural damping $\eta_{s t r}=0.1$, foundation damping $\eta_{S S I}=0.4$, and $k_{\mathrm{SSI}}=$ $693525300 \mathrm{~N} / \mathrm{m}$. It worth mentioning that there are zones where the structure has a damping effect on the surrounding soil by decreasing the peak response and sectors where the structure induces a detrimental effect by increasing the maximum response of the soil. In particular, beneficial effects of about $-21 \%$ are observed for fundamental structural periods close by the fundamental period of the site deposit $\left(\mathrm{T}_{\text {soil }}=0.3 \mathrm{~s}\right)$ whereas for structural period shorter than the soil period amplifications of the response are obtained up to $+26 \%$, in agreement with results observed by Kobori et al. [35]. In Figure 6b a heavier mass, $m_{\mathrm{str}}=500000 \mathrm{~kg}$ has been used; it could be observed higher deamplifications of the response for a broader range of structural periods and distances with reductions up to $27 \%$ are obtained for structural periods close to the fundamental period of the site deposit. Amplifications higher than $35 \%$ of the free field motion are also achieved. Also, it is worth noting that the foundation damping strongly affects the results, the smaller is the damping the higher is the influence on the wave field as depicted in Figure 7a-b for the same previous cases by considering a foundation damping $\eta_{S S I}=$ 0.1. Remarkably, amplifications above $45 \%$ and $95 \%$ of the free field response are achieved around a structure of mass $m_{\text {str }}=350000 \mathrm{~kg}$ and $m_{\text {str }}=500000 \mathrm{~kg}$, respectively. Note that the shaded area in Figure 6 and Figure 7 the distance $d$ is lower than the radius of the foundation, therefore (Eq. 18) does not apply. 

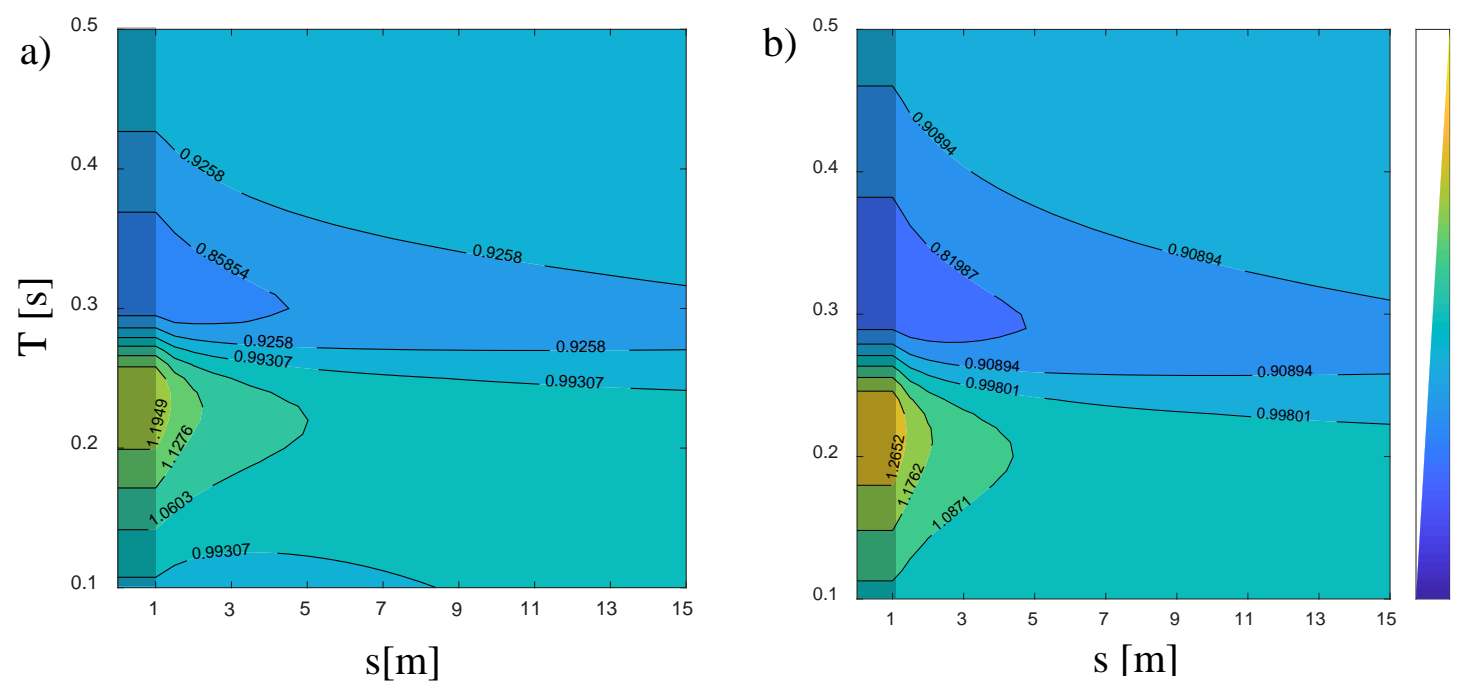

Figure 6 Ratio $\Delta$ of the $50 \%$ fractiles of the peak ground acceleration around a structure with a) $m_{\text {str }}$ $=350,000 \mathrm{~kg}$ and $b) m_{s t r}=500,000 \mathrm{~kg}$ for foundation damping $\eta_{S S I}=0.4$.
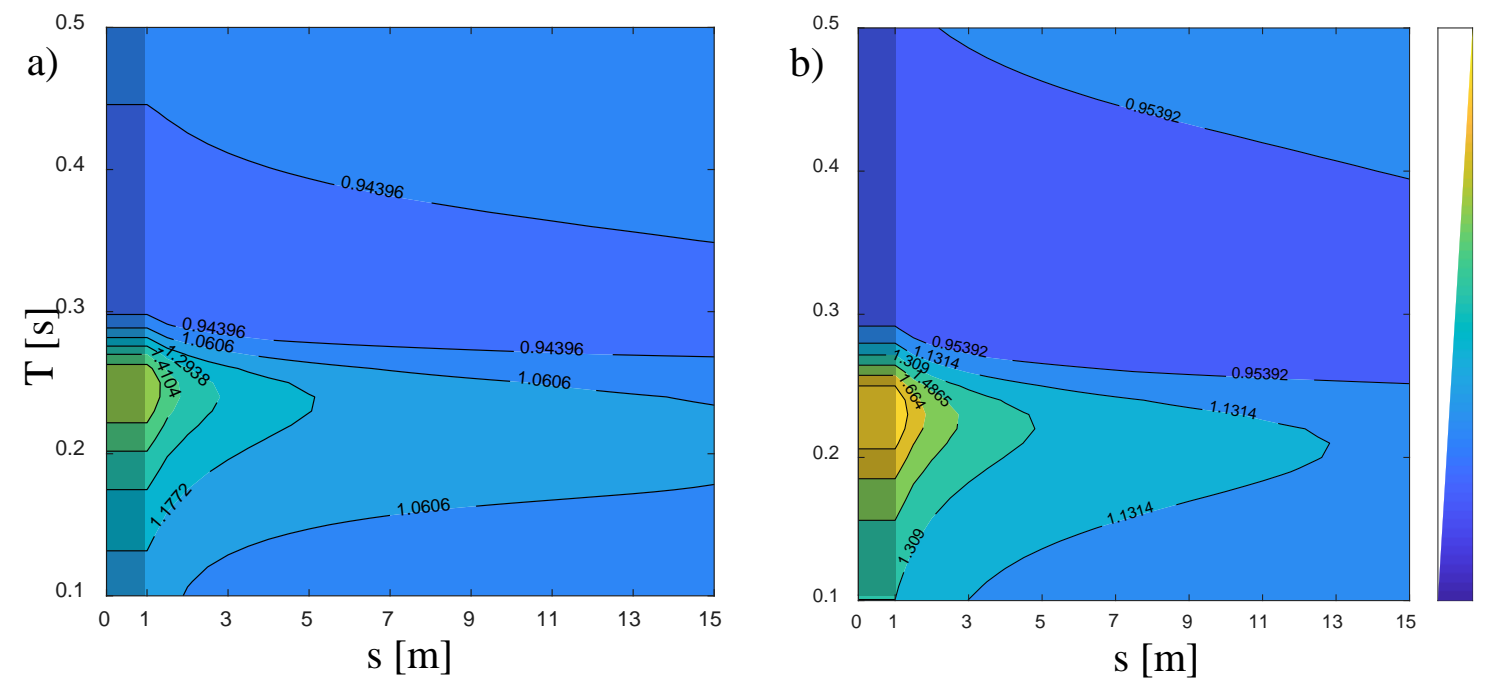

Figure 7 Ratio $\Delta$ of the $50 \%$ fractiles of the peak ground acceleration around a structure with a) $m_{\text {str }}$ $=350,000 \mathrm{~kg}$ and $b) m_{s t r}=500,000 \mathrm{~kg}$ for foundation damping $\eta_{S S I}=0.1$.

The proposed stationary power spectral density functions of the ground motion in proximity of an individual vibrating structure are represented in Figure 8. Specifically two different fixed base structural periods $\mathrm{T}=\frac{2 \pi}{\omega_{0}}=0.2 \mathrm{~s}$ and $\mathrm{T}=0.3 \mathrm{~s}$ have been selected to consider two possible scenarios in which the vibrating structure either increases or reduces the nearby ground motion energy. As proved analytically in the previous sections the larger the distance from the vibrating structure the closer the proposed model is to the power spectral density function of 
the free field ground motion (given by Eq. 47). Figure 8a-b shows the variation of the power spectral density around the structure of period $\mathrm{T}=0.2 \mathrm{~s}$ with the increase of the distance, for short distances the power spectral density manifests the higher peak gradually decreasing to the free field ground motion response. In Figure 8c-d is depicted the variation of the power spectral density around the structure of period $\mathrm{T}=0.3 \mathrm{~s}$, for short distances two peaks corresponding to the soil natural frequency and structural frequency can be observed, and with the increment of the distance, gradually the first decreases while the latter increases approaching the free field response.

The impact of a cluster of two structures on the ground motion at the soil surface is also evaluated in Figure 10; the induced wave field is assessed by using Eq. (37). The model used for simulating the wave field around a single structure is depicted in Figure 5. Figure 9 shows the ratio, $\Delta(s, \mathrm{~T})$ defined in Eq. (46), of the $50 \%$ fractile of the peak acceleration at various positions, $s$, induced by a cluster of two vibrating structures with same fundamental periods, $\mathrm{T}$ , relative distance $4 \mathrm{~m}$, structural damping $\eta_{s t r}=0.1$ and foundation damping $\eta_{f}=0.4$. The origin, $s=0$, is set on axis of symmetry representing the mid-span between two structures.

Figure 9a shows the case in which the structures with mass, $\mathrm{m}_{\mathrm{str}}^{1} \equiv \mathrm{m}_{\mathrm{str}}^{2}=350,000 \mathrm{~kg}$ and in Figure $9 \mathrm{~b}$ the case with structural masses, $\mathrm{m}_{\mathrm{str}}^{1} \equiv \mathrm{m}_{\mathrm{str}}^{2}=500,000 \mathrm{~kg}$. Due to the symmetry of the problem, only the wave field located in the positive quadrant of the coordinate system is depicted. 

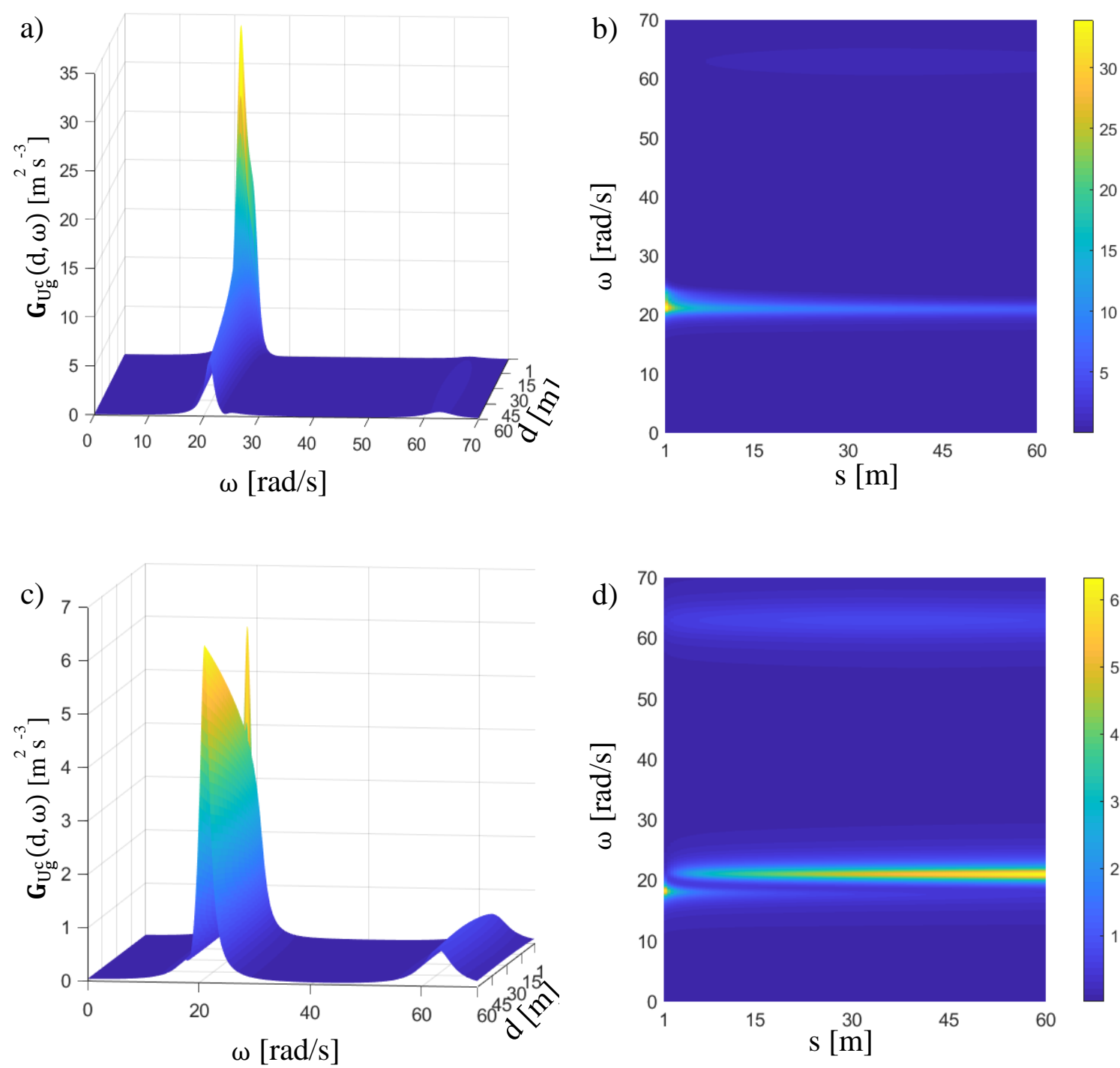

Figure 8 PSD in proximity of the vibrating structure with period $T=0.2 \mathrm{~s}$ a) $3 D$ view $b$ ) top view and $T=0.3 \mathrm{~s}$ c) $3 D$ view d) top view

Areas of high amplification of the response is achieved for structural periods shorter than the soil deposit natural frequency as previously observed in Figure 6; in particular, a constructive interference of the waves is obtained in the zone between the two foundations at a distance $\mathrm{s}=$ $0-1 \mathrm{~m}$. Conversely, for longer periods a mitigation of the free field motion is obtained with reductions up to $42 \%$ (at $\mathrm{T}=0.35 \mathrm{~s}$ ). 

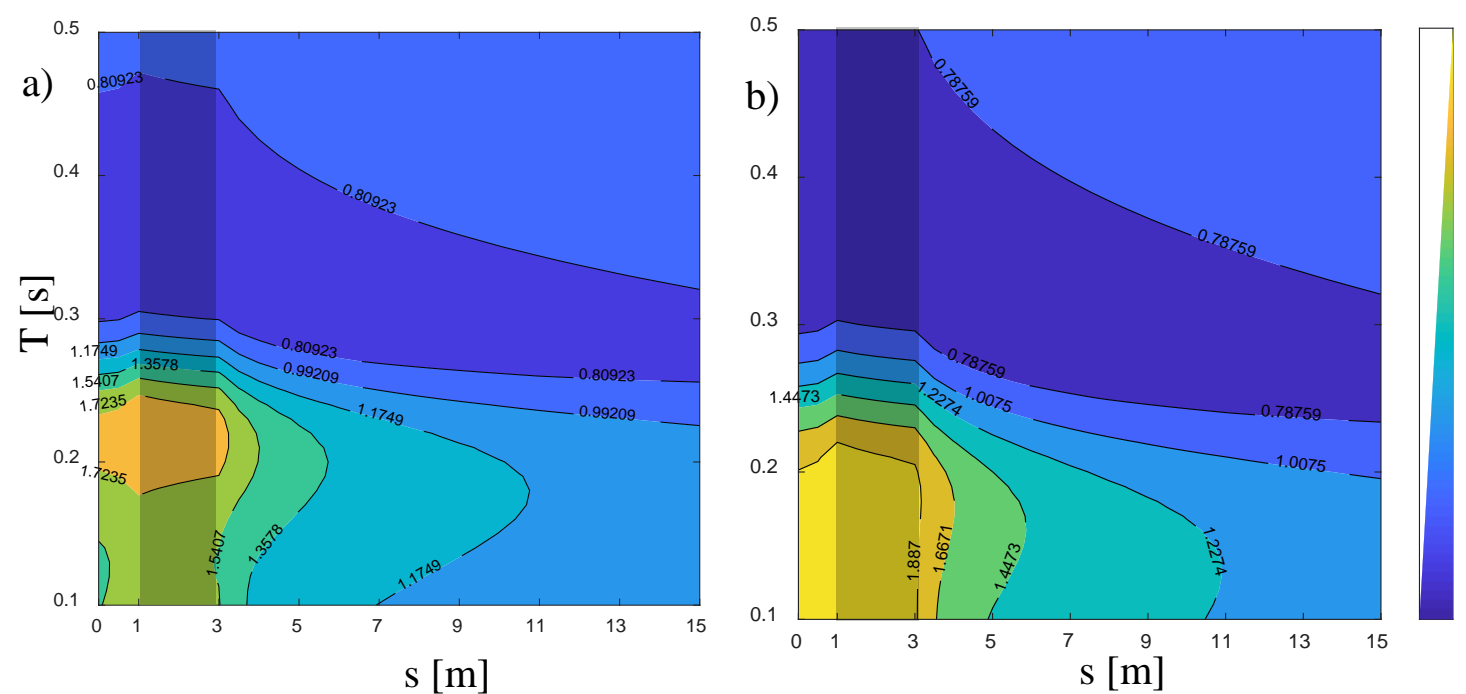

Figure 9 Ratio $\Delta$ of the 50\% fractiles of the peak ground acceleration around two structures with a) $m_{\text {str }}^{1} \equiv m_{\text {str }}^{2}=350,000 \mathrm{~kg}$, and b) $m_{\text {str }}^{1} \equiv m_{\text {str }}^{2}=500,000 \mathrm{~kg}$

\subsection{Comparison of the proposed analytical model with MCS}

In this section the proposed ground motion models for single structure presented in Eq. (19) and for cluster of structures determined in Eq. (37) are compared with the results determined through a pertinent Monte Carlo study. It has to be emphasized that to the best knowledge of the authors there is no available analytical exact solution that can be used as a benchmark, therefore a Finite Element model has been developed in ADINA ver 9.4.1 to reproduce similar scenarios. The case depicted in Figure 2 is studied first. Values evaluated from the finite element model, are reported in Table 1.

The soil domain, characterized by average shear wave velocity, $\mathrm{V}_{\mathrm{s}}=400 \mathrm{~m} / \mathrm{s}$, is $30 \mathrm{~m}$-deep and $800 \mathrm{~m}$-wide in order to avoid reflections of the waves on the lateral free boundaries of the domain. The soil domain is modelled with 9-Node Quadrilateral Elements under plane strain conditions without vertical degree of freedom. A Rayleigh-type damping is applied by considering a loss factor, $\eta=0.1$, calibrated at the natural periods of structure and soil deposit. Seismic excitation is applied as prescribed acceleration to the bottom of the soil deposit. Monte Carlo simulation is performed by considering 20 Gaussian clipped white noise samples $\left(\mathrm{G}_{W}=\right.$ 
$0.04 \mathrm{~m}^{2} s^{-3}$ ) with $500 \mathrm{~Hz}$ cut-off frequency. The power spectral density functions obtained on the surface at B $(s=3 \mathrm{~m})$ through the Monte Carlo Simulation are compared with the proposed analytical PSD defined by Eq. (19) in Figure 10. It can be seen that the proposed curve matches quite well the average PSD obtained by MCS. Despite, the discrepancies mainly due to the different assumptions made in the two models both the proposed model and the MCS capture the relevant effect of the vibrating structure on the ground motion. In the same Figure 10, the PSD of the free field motion $U_{g}(\omega)$ obtained from Eq. (47), and indicated through a dashed line, is superimposed in order to visualize the effect of the wave field radiated by the structure.

Table 1 Mechanical parameters used for the proposed discrete model

\begin{tabular}{|c|c|c|c|c|c|}
\hline & $\mathrm{T}$ & $k_{s t r}$ & $m_{s t r}$ & $k_{\mathrm{SSI}}$ & $m_{\mathrm{f}}$ \\
\hline \multirow{2}{*}{ Structure 1} & $0.2 s$ & $197392088 \mathrm{~N} / \mathrm{m}$ & $350000 \mathrm{~kg}$ & $693525300 \mathrm{~N} / \mathrm{m}$ & $15400 \mathrm{~kg}$ \\
\hline & $0.3 s$ & $3.4544 \mathrm{e}+08 \mathrm{~N} / \mathrm{m}$ & $350000 \mathrm{~kg}$ & $693525300 \mathrm{~N} / \mathrm{m}$ & $15400 \mathrm{~kg}$ \\
\hline
\end{tabular}
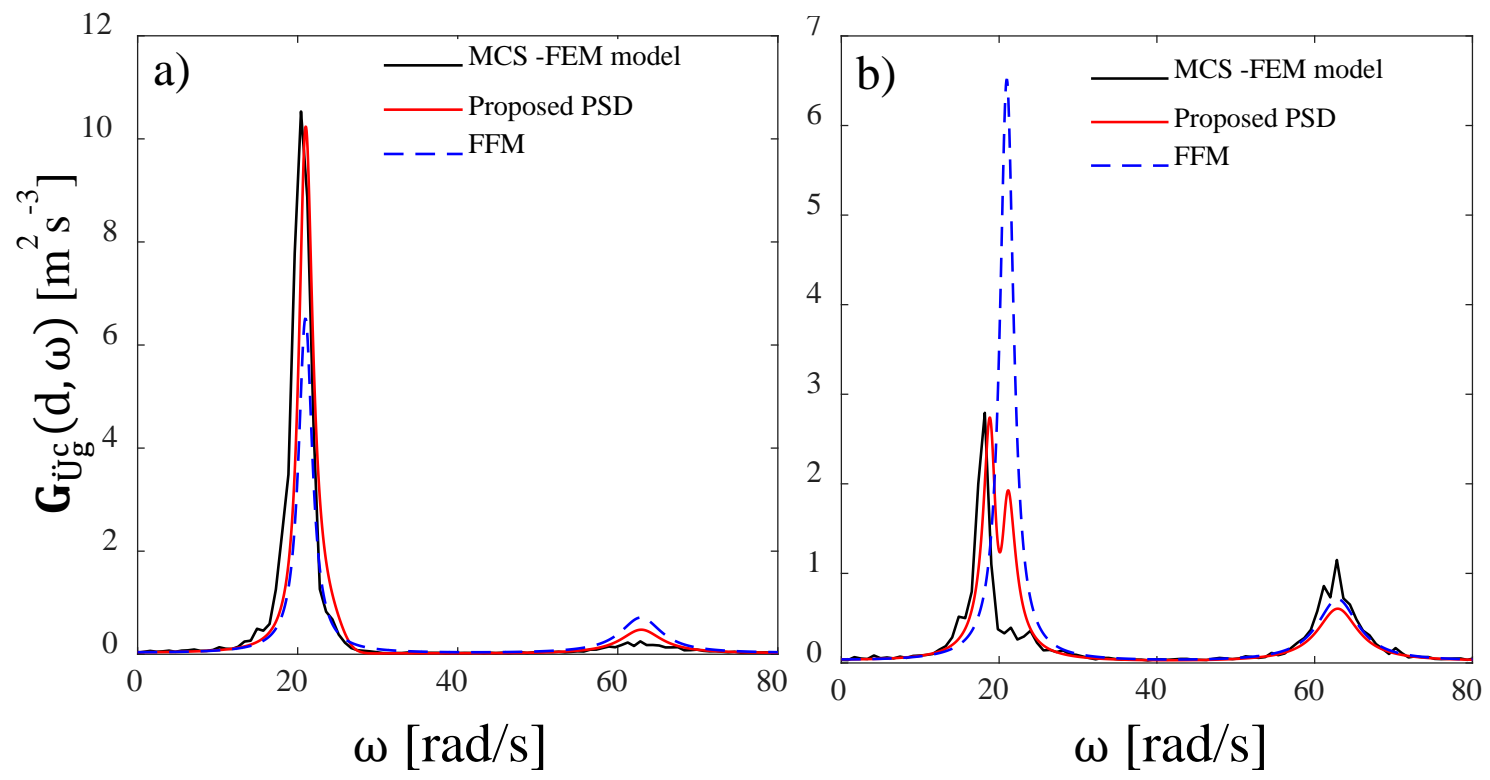

Figure 10 PSD at point B at 3m distance obtained by the proposed PSD model and comparison with MCS for structural period a) $T=0.2 \mathrm{~s}$ and $b$ ) $T=0.3 \mathrm{~s}$. 
The scenario used for simulating the wave field around a cluster of structures is depicted in Figure 5. Values used for the analytical formulation reported in Table 2 while soil and damping data are those used previously. Figure 11 shows the power spectral density function of the altered seismic wave field at the distance of $6 \mathrm{~m}$ induced by two structures with identical period $\mathrm{T}$ (i.e, Figure 11a $\mathrm{T}=0.2 \mathrm{~s}$ and Figure $11 \mathrm{~b} \mathrm{~T}=0.3 \mathrm{~s}$ ). The proposed formulation of Eq. (37) represented by a red continuous curve matches quite well the PSD determined by the MCS.

Table 2 Mechanical parameters used for the proposed discrete model of cluster of structures

$$
\begin{array}{ccccc}
\text { Structures 1-2 } & k_{\text {str }} & m_{\text {str }} & k_{\text {SSI }} & m_{\mathrm{f}} \\
\cline { 3 - 5 } \mathrm{T}=0.2 \mathrm{~s} & 197392088 \mathrm{~N} / \mathrm{m} & 200000 \mathrm{~kg} & 394970000 \mathrm{~N} / \mathrm{m} & 15400 \mathrm{~kg} \\
\cline { 3 - 5 } \mathrm{T}=0.3 \mathrm{~s} & 153527180 \mathrm{~N} / \mathrm{m} & 350000 \mathrm{~kg} & 394970000 \mathrm{~N} / \mathrm{m} & 15400 \mathrm{~kg}
\end{array}
$$
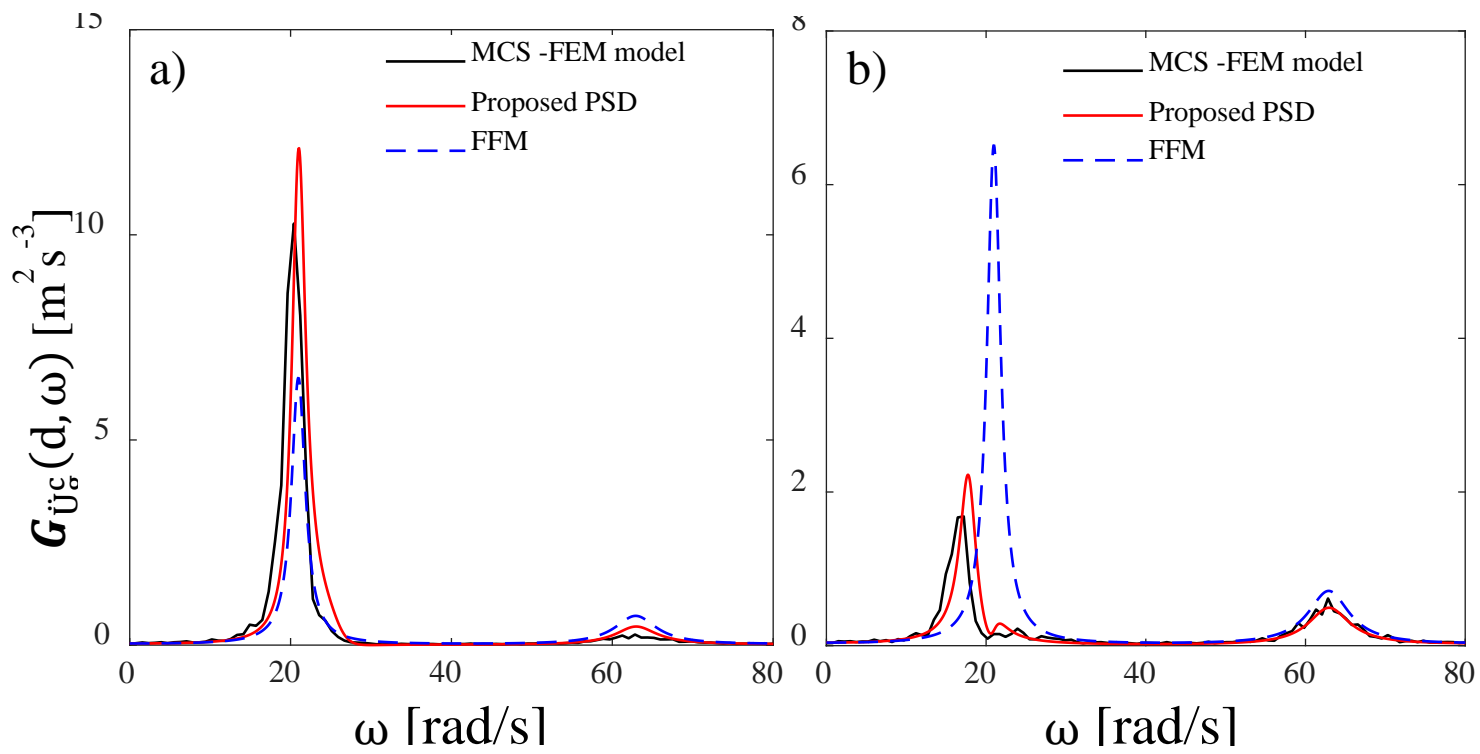

Figure 11 PSD at $s=6 m$ and comparison with MCS for a cluster of structures with the same structural periods a) $T=0.2 \mathrm{~s}$ and $b$ ) $T=0.3 \mathrm{~s}$. 


\subsection{Influence of the modified ground motion on the structural response}

Finally, an application of the proposed ground motion model for the stochastic seismic analysis of a structure in urban environment is shown. Consider the scenario in Figure 5 in which it is aimed to calculate the response of the structure 2 located at the point B influenced by the adjacent building 1 at location A placed at a distance, $\mathrm{s}=3 \mathrm{~m}$. The two structures are characterized by structural period $\mathrm{T}^{A}=0.2 \mathrm{~s}$ and mass $m_{\mathrm{str}}^{A}=500000 \mathrm{~kg}$ and structural period $\mathrm{T}^{B}=0.5 \mathrm{~s} m_{\text {str }}^{B}=200000 \mathrm{~kg}$ for structure 1 and 2, respectively. A Monte Carlo Simulation with 30 stationary Gaussian white noises is performed.

The average peak acceleration of the structure 2 at location B determined through the coupled FE model (including structure 1) is equal to $16.64 \frac{m}{s^{2}}$ and will be considered the benchmark value (see Table 3). The 50\% peak acceleration fractile obtained by the proposed PSD using the procedure described in Section 4 is $17.36 \frac{m}{s^{2}}$, hence, with a small error of $4.33 \%$ with respect the benchmark value. It is worth noting that by using a conventional approach where the influence of the nearby vibrating building is neglected on the building, namely by considering the structure 2 by itself, the average peak structural acceleration would be 12.27 $\frac{m}{s^{2}}$, hence, $35.69 \%$ lower than the actual peak dynamic response.

Table 3 Analytical and Numerical results of the application on the proposed PSD for design in urban environemnt

\begin{tabular}{cccccc}
$\begin{array}{c}\text { Structure 2 } \\
\text { (Location } \\
\text { B) }\end{array}$ & $\begin{array}{c}\text { MCS }- \\
\text { coupled } \\
\text { system } \\
\text { (benchmark) }\end{array}$ & $\begin{array}{c}\text { MCS }- \\
\text { conventional } \\
\text { procedure }\end{array}$ & $\begin{array}{c}\text { Relative } \\
\text { Error using } \\
\text { conventional } \\
\text { procedure }\end{array}$ & $\begin{array}{c}\text { Proposed } \\
\text { PSD for } \\
\text { urban } \\
\text { environment }\end{array}$ & $\begin{array}{c}\text { Relative } \\
\text { Error } \\
\text { using the } \\
\text { proposed } \\
\text { model }\end{array}$ \\
\hline $\begin{array}{c}\text { Median } \\
\text { Peak }\end{array}$ & & & & & \\
$\begin{array}{c}\text { acceleration } \\
\frac{m}{s^{2}}\end{array}$ & 16.64 & 12.27 & $-35.69 \%$ & 17.36 & $4.33 \%$
\end{tabular}




\section{$6 \quad$ Concluding remarks}

In this paper, a stochastic ground motion model for urban environment is proposed. A discrete model of structure on compliant foundation simulating the soil-structure interaction effects has been coupled with an analytical model of cylindrical wave propagation to capture the attenuation effects with distance of the vibrations induced by a vibrating structure. Relevant amplifications over $45 \%$ of the free field peak ground motion have been obtained. Parametric studies have been performed to highlight the need to consider a modified free field ground motion within the urban environment in line with current research in literature. Results obtained by the proposed ground motion model in urban environment has been verified through pertinent Monte Carlo studies on a numerical finite element model. Finally, an application of the proposed model to the stochastic seismic analysis of a structure in proximity of an existing one has been carried out to show its relevance for seismic design purposes. The proposed model was able to well predict the dynamic response of a structure collocated in proximity of another building with a small error of $4 \%$ while a relevant under estimation of about $36 \%$ has been obtained through traditional approach. To the best knowledge of the authors the model proposed in this paper represents the first stochastic ground motion model for urban environment and probably this is the most important outcome of the proposed study. Closed form solutions have also been proposed for different scenarios. Despite the various assumptions and approximation adopted in the proposed approach results appears in excellent agreement with those provided in literature and through alternative numerical models. Further studies will consider more complex interaction phenomena including more advanced wave field radiated by the individual structure and mutual interactions for cluster of buildings. 


\section{References}

[1]G. Deodatis, "Non-stationary stochastic vector processes: seismic ground motion applications,” Probabilistic Engineering Mechanics, vol. 11, no. 3, pp. 149-167, Jul. 1996.

[2]G. Pousse, L. F. Bonilla, F. Cotton, and L. Margerin, "Nonstationary Stochastic Simulation of Strong Ground Motion Time Histories Including Natural Variability: Application to the KNet Japanese Database,” Bulletin of the Seismological Society of America, vol. 96, no. 6, pp. 2103-2117, Dec. 2006.

[3]P. D. Spanos, A. Giaralis, and N. P. Politis, “Time-frequency representation of earthquake accelerograms and inelastic structural response records using the adaptive chirplet decomposition and empirical mode decomposition," Soil Dynamics and Earthquake Engineering, vol. 27, no. 7, pp. 675-689, Jul. 2007.

[4]A. Zerva, Spatial variation of seismic ground motions: modeling and engineering applications. Boca Raton: CRC Press, 2009.

[5]S. Rezaeian and A. Der Kiureghian, "Simulation of synthetic ground motions for specified earthquake and site characteristics,” Earthquake Engineering \& Structural Dynamics, p. n/an/a, 2010.

[6]P. Cacciola and G. Deodatis, “A method for generating fully non-stationary and spectrumcompatible ground motion vector processes,” Soil Dynamics and Earthquake Engineering, vol. 31, no. 3, pp. 351-360, Mar. 2011.

[7]P. Cacciola and I. Zentner, "Generation of response-spectrum-compatible artificial earthquake accelerograms with random joint time-frequency distributions,” Probabilistic Engineering Mechanics, vol. 28, pp. 52-58, Apr. 2012. 
[8]P. Cacciola, L. D’Amico, and I. Zentner, "New insights in the analysis of the structural response to response-spectrum-compatible accelerograms,” Engineering Structures, vol. 78, pp. 3-16, Nov. 2014.

[9]D. Wang, Z. Fan, S. Hao, and D. Zhao, “An evolutionary power spectrum model of fully nonstationary seismic ground motion,” Soil Dynamics and Earthquake Engineering, vol. 105, pp. 1-10, Feb. 2018.

[10]D. Clouteau and D. Aubry, "Modifications of the Ground Motion in Dense Urban Areas," Journal of Computational Acoustics, vol. 9, no. 4, pp. 1659-1675, Dec. 2001.

[11]M. Kham, J.-F. Semblat, P.-Y. Bard, and P. Dangla, "Seismic Site-City Interaction: Main Governing Phenomena through Simplified Numerical Models,” Bulletin of the Seismological Society of America, vol. 96, no. 5, pp. 1934-1951, Oct. 2006.

[12]Y. Isbiliroglu, R. Taborda, and J. Bielak, “Coupled Soil-Structure Interaction Effects of Building Clusters During Earthquakes,” Earthquake Spectra, vol. 31, no. 1, pp. 463-500, Feb. 2015.

[13]A. Wirgin, “Earthquakes in cities revisited,” arXiv:1607.08856 [physics], Jul. 2016.

[14]P. Guéguen, P.-Y. Bard, and F. Chavez-Garcia, "Site-City Interaction in Mexico City-Like environments: An Analytical Study,” Bulletin of the Seismological Society of America, vol. 92, no. 2, pp. 794-811, 2002.

[15]C. Tsogka and A. Wirgin, "Simulation of seismic response in an idealized city," Soil Dynamics and Earthquake Engineering, vol. 23, no. 5, pp. 391-402, Jul. 2003.

[16]C. Boutin and P. Roussillon, “Assessment of the urbanization effect on seismic response,” Bulletin of the Seismological Society of America, vol. 94, no. 1, pp. 251-268, 2004.

[17]J. Groby, C. Tsogka, and A. Wirgin, "Simulation of seismic response in a city-like environment,” Soil Dynamics and Earthquake Engineering, vol. 25, no. 7-10, pp. 487-504, Aug. 2005. 
[18]M. Ghergu and I. R. Ionescu, "Structure-soil-structure coupling in seismic excitation and 'city effect,'” International Journal of Engineering Science, vol. 47, no. 3, pp. 342-354, Mar. 2009.

[19]D. Sahar, J. P. Narayan, and N. Kumar, "Study of role of basin shape in the site-city interaction effects on the ground motion characteristics,” Natural Hazards, vol. 75, no. 2, pp. 1167-1186, Jan. 2015.

[20]J. P. Wolf, Dynamic soil-structure interaction. Englewood Cliffs, N.J.: Prentice-Hall, 1985. [21]Y. Hisada, “An efficient method for computing Green’s functions for a layered half-space with sources and receivers at close depths,” Bulletin of the Seismological Society of America, vol. 84, no. 5, pp. 1456-1472, Oct. 1994.

[22]Y. Hisada, “An efficient method for computing Green’s functions for a layered half-space with sources and receivers at close depths (part 2)," Bulletin of the Seismological Society of America, vol. 85, no. 4, pp. 1080-1093, Aug. 1995.

[23]P. M. Morse and K. U. Ingard, Theoretical acoustics. Princeton, N.J: Princeton University Press, 1986.

[24]R. Dobry and G. Gazetas, "Simple method for dynamic stiffness and damping of floating pile groups,” Geotechnique, London, vol. 38, no. 4, pp. 557 - 574, 1988.

[25]P. C. Jennings and J. Bielak, "Dynamics of building-soil interaction," Bulletin of the Seismological Society of America, vol. 63, no. 1, pp. 9-48, Feb. 1973.

[26]J. Bielak, "Dynamic behaviour of structures with embedded foundations," Earthquake Engineering \& Structural Dynamics, vol. 3, no. 3, pp. 259-274, 1974.

[27]S. Carbonari, M. Morici, F. Dezi, and G. Leoni, “A lumped parameter model for timedomain inertial soil-structure interaction analysis of structures on pile foundations," Earthquake Engineering \& Structural Dynamics, vol. 47, no. 11, pp. 2147-2171, Sep. 2018. [28]R. W. Clough and J. Penzien, Dynamics of structures. New York: McGraw-Hill, 1975. 
[29]P. Cacciola, “A stochastic approach for generating spectrum compatible fully nonstationary earthquakes,” Computers \& Structures, vol. 88, no. 15-16, pp. 889-901, Aug. 2010.

[30]A. Giaralis and P. D. Spanos, “Derivation of response spectrum compatible non-stationary stochastic processes relying on Monte Carlo-based peak factor estimation,” Earthquakes and Structures, vol. 3, no. 5, pp. 719-747, Sep. 2012.

[31]S. L. Kramer, Geotechnical earthquake engineering. Upper Saddle River, N.J.: Prentice Hall, 1996.

[32]A. D. Kiureghian, “A COHERENCY MODEL FOR SPATIALLY VARYING GROUND MOTIONS,” Earthquake Engineering \& Structural Dynamics, vol. 25, no. 1, pp. 99-111, Jan. 1996.

[33]H. G. Poulos, “Analysis of the Settlement of Pile Groups,” Géotechnique, vol. 18, no. 4, pp. 449-471, Dec. 1968.

[34] Vanmarcke, E.H., Gasparini, D.A. 1977, Simulated earthquake ground motions. Proc. 4th Int. Conf. on Smirt, K1/9, San Francisco1977.

[35]T. Kobori, R. Minai, and K. Kusakabe, “Dynamical characteristics of soil-structure crossinteraction systems,” International Journal of Rock Mechanics and Mining Sciences \& Geomechanics Abstracts, vol. 11, no. 8, p. A175, Aug. 1974. 